\title{
EVALUATION OF PILE'S BUCKLING UNDER AXIAL LOAD BY B-SPLINE METHOD AND COMPARISON WITH FINITE ELEMENT METHOD AND EXACT SOLUTION
}

\author{
A. Moghaddam ${ }^{a}$, A. Nayeri ${ }^{\text {a* }}$, S.M. Mirhosseini ${ }^{\mathrm{a}}$ \\ a Department of Civil Engineering, Arak Branch, Islamic Azad University, Arak, Iran \\ E-mails: Amir.moughaddam@gmail.com, Arash.nayeri@gmail.com*, M.mirhosayni@gmail.com
}

Received: 13.06.2018 / Accepted: 10.09.2018 / Revised: 20.11.2018 / Available online: 15.12.2018

DOI: 10.2478/jaes-2018-0015

KEY WORDS: B-Spline, Finite element, Buckling, Exact solution, Nonlinear horizontal reaction coefficient.

\begin{abstract}
:
Although various analytical and numerical methods have been proposed by researchers to solve equations, but use of numerical tools with low volume calculations and high accuracy instead of other numerical methods with high volume calculations is inevitable in the analysis of engineering equations. In this paper, B-Spline spectral method was used to study buckling equations of the piles. Results were compared with the calculated amounts of the exact solution and finite element method. Uniform horizontal reaction coefficient has been used in most of proposed methods for analyzing buckling of the pile on elastic base. In reality, soil horizontal reaction coefficient is nonlinear along the pile. So, in this research by using B-Spline method, buckling equation of the pile with nonlinear horizontal reaction coefficient of the soil was investigated. It is worth mentioning that B-Spline method had not been used for buckling of the pile.
\end{abstract}

\section{INTRODUCTION}

Use of simple and precise tools in calculations and numerical analyses of engineering equations is essential. B-Spline has been used in different conditions of engineering by various researchers (Andrade et al. 2010; Moghaddam et al. 2012; Shariyat and Asemi, 2014). But use of this tool for buckling analyses of piles under the structures has not been reported yet. In this research program, B-Spline method was utilized in numerical solution of buckling equation of the beam on elastic base as shown in Figure 1. Basic equation for buckling of columns under the effect of lateral springs based on beam on elastic base is (Hetenyi, 1960):

$$
E I^{d^{4} y} / d x^{4}+P d^{2} Y / d x^{2}+K_{s} Y=0
$$

where: $E I=$ pile stiffness

$P=$ vertical load on pile

$K_{s}=$ horizontal reaction coefficient

$Y=$ lateral displacement of pile under vertical load

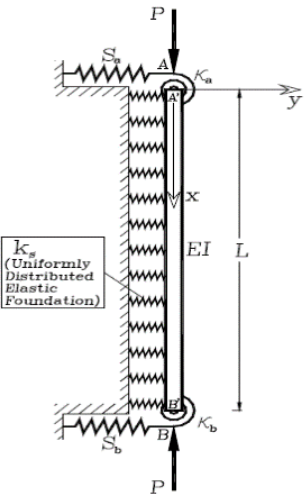

Figure 1. Column or pile under vertical load in beam on elastic base condition

In engineering analyses based on beam on elastic base, horizontal reaction coefficient represents characteristics of soil and surrounding materials of pile or column. The boundary conditions in Eq (1) based on Figure 1 are (Aristizabe Ochoa, 2013):

$$
\begin{array}{lr}
X=l & E I^{d^{2} y} / d x^{2}+k_{b}{ }^{d y} / d_{x}=M_{b} \\
X=0 & -E I^{d^{2} y} / d x^{2}+k_{a} d_{y} / d_{x}=M_{a} \\
X=l & -E I^{d^{3} y / d x^{3}-P}{ }^{d_{y}} / d_{x}+S_{b} y=V_{b} \\
X=0 & E I^{d^{3} y} / d x^{3}+P d_{y} / d_{x}+S_{a} y=V_{a}
\end{array}
$$

where: $M_{a}, M_{b}=$ overturning moments at $\mathrm{A}$ and $\mathrm{B}$

\footnotetext{
* Corresponding author: Arash NAYERI, e-mail: Arash.nayeri@gmail.com
} 


$$
V_{a}, V_{b}=\text { Shears at } \mathrm{A} \text { and } \mathrm{B}
$$

In 1960, Hetenyi proposed a method for solving buckling equation (Hetenyi 1960). This method became a base for analytical methods in calculation of buckling behaviour. By continuing Hetenyi method, pile's buckling critical load for semirigid joints in supports was investigated by Aristizabe-Ochoa (2013). West et al. (1997) studied buckling of the pile with various support's conditions and different modes, with analytical solution of buckling equation. Then, this analytical method was extended by adding friction between soil and pile to the equations and partially embedded piles by other researchers (West et al, 1997; Heelis and West, 1999; Heelis et al, 2004). Deng et al (2017) presented an analytical method on the basis of Modified Vlasov Foundation Model. They reported that Poisson's ratio did not have any effect on buckling critical load. It is worth noting that soil's horizontal reaction coefficient along the pile was assumed uniform in calculating buckling equation. Although many researches had been conducted on piles' buckling capacity, but Bhattacharya (2004) researches on 15 constructed piles which had experienced buckling failure under different loads; led to onset of detailed investigations on buckling of the piles in recent years. These researchers believed that buckling critical load in different codes should be reinvestigated. Moreover, the effect of buckling on liquefaction phenomenon under dynamic loads should be studied (Bhattacharya et al. 2004; Bhattacharya et al. 2005). In 2013, Law Chi Wai investigated buckling equation by using finite difference numerical method. He proposed pile's buckling equivalent length in various conditions (Law Chi Wai 2013). It is worth mentioning that in all of the exact solutions and numerical methods for buckling equation on the basis of beam on elastic base, the amount of horizontal reaction coefficient was supposed uniform or with linear variations along the pile. But the actual value for horizontal reaction coefficient along the pile is non-uniform and nonlinear (Terzaghi 1955; Davisson and Perkash, 1963). One of the main objectives of this research was extending these methods by using B-Spline numerical method with nonlinear reaction coefficient along the pile. It should be noted that the amount of horizontal reaction coefficient along the pile should be modelled nonlinear in applied analysis of engineering.

\section{B-SPLINE METHOD}

B-Spline method is a spectral method for analyzing equations. Since buckling equation is fourth order, fifth degree B-Spline base equations should be used for analyzing. Various degrees of B-Spline equations can be found in (Hikmet Caglar and NazanCaglar 2008; De Boor 1978; Piegl and Tiller 1995).

Fifth degree B-Spline base equations are presented in Eqs. (3), with equally-spaced knots of a partition $\pi: \mathrm{a}=\mathrm{x} 0<\mathrm{x} 1<\ldots<\mathrm{xn}=$ $\mathrm{b}$ on $[\mathrm{a}, \mathrm{b}]$. Let $\mathrm{S}_{5}[\pi]$ be the space of continuously-differentiable, piecewise, fifth-degree polynomials on $\pi$, that is, $S_{5}[\pi]$ is the space of fifth-degree Splines on $\pi$. Consider the B-Splines basis in $\mathrm{S}_{5}[\pi]$. The fifth-degree B-Splines are defined as Eqs. (3) (Hikmet Caglar and Nazan Caglar 2008):

$$
\begin{aligned}
& \mathbf{B}_{\mathbf{0}}(\mathbf{x})= \\
& \frac{1}{120 \mathrm{~h}^{5}}\left(x^{5}\right) \quad 0 \ll x<h \\
& \frac{1}{120 \mathrm{~h}^{5}}\left(-5 x^{5}+30 h x^{4}-60 h^{2} x^{3}+\right. \\
& \left.60 h^{3} x^{2}-30 h^{4} x+6 h^{5}\right) \quad h \ll x<2 h
\end{aligned}
$$

$$
\begin{aligned}
& \frac{1}{120 h^{5}}\left(10 x^{5}-120 h x^{4}+540 h^{2} x^{3}-\right. \\
& \left.1140 h^{3} x^{2}+1170 h^{4} x-474 h^{5}\right) \quad 2 h \ll x<3 h \\
& \frac{1}{120 h^{5}}\left(-10 x^{5}+180 h x^{4}-1260 h^{2} x^{3}+\right. \\
& \left.4260 h^{3} x^{2}-6930 h^{4} x+4386 h^{5}\right) \quad 3 h \ll x<4 h \\
& \frac{1}{120 \mathrm{~h}^{5}}\left(5 x^{5}-120 h x^{4}+1140 h^{2} x^{3}-\right. \\
& \left.5340 h^{3} x^{2}+12270 h^{4} x-10974 h^{5}\right) \quad 4 h \ll x<5 h \\
& \frac{1}{120 \mathrm{~h}^{5}}\left(-x^{5}+30 h x^{4}-360 h^{2} x^{3}+\right. \\
& \left.2160 h^{3} x^{2}-6480 h^{4} x+7776 h^{5}\right) \quad 5 h \ll x<6 \\
& B_{i-1}(x)=B_{0}(x-(i-l) h, \quad i=2,3, \ldots
\end{aligned}
$$

General equation of B-Spline line which is the approximate solution of the equation is defined as Eq (4):

$$
\mathrm{S}(x)=\sum_{i=0}^{n} B_{i, \rho}(x) C_{i}
$$

where: $C_{i}=$ are unknown real coefficient

$$
B_{i}=\text { unknown real coefficient and B-Spline function }
$$

By equating $y(x)$ with the value of B-Spline general function i.e. $\mathrm{y}(\mathrm{x})=\mathrm{S}(\mathrm{x}), \mathrm{Eq}(5)$ is obtained.

$$
y(x)=\sum_{i=0}^{n} B_{i, 5}(x) C_{i}
$$

As mentioned before, $\mathrm{B}_{\mathrm{i}}(\mathrm{x})$ is $\mathrm{B}-$-Spline base function in $\mathrm{Eq}(5)$. Since buckling general equation is fourth order, base functions with fifth degree should be used.

By substituting the values of fifth degree B-Spline functions presented in $\mathrm{Eq}$ (3) in main equation of B-Spline, Eq (6a) is obtained. Sequential derivation from this equation leads to Eqs. (6b) to (6e):

$$
\begin{aligned}
& y(x)=C_{1} B_{1}(x)+c_{2} B_{2}(x)+C_{3} B_{3}(x)+\cdots \\
& y^{(1)}(x)=C_{1} B_{1}^{(1)}(x)+C_{2} B_{2}^{(1)}(x)+C_{3} B_{3}^{(1)}(x)+\cdots \\
& y^{(2)}(x)=C_{1} B_{1}^{(2)}(x)+C_{2} B_{2}^{(2)}(x)+C_{3} B_{3}^{(2)}(x)+\cdots \\
& y^{(3)}(x)=C_{1} B_{1}^{(3)}(x)+C_{2} B_{2}^{(3)}(x)+C_{3} B_{3}^{(3)}(x)+\cdots \\
& y^{(4)}(x)=C_{1} B_{1}^{(4)}(x)+C_{2} B_{2}^{(4)}(x)+C_{3} B_{3}^{(4)}(x)+\cdots
\end{aligned}
$$

$B_{i}^{n}(x)$ Coefficients and their derivations in above equations are calculated and presented in Table 1 .

Table 1.Values of $\mathrm{B}_{\mathrm{i}}, B_{i}^{n}(x)$

\begin{tabular}{cccccccc} 
& $x_{i}$ & $x_{i+1}$ & $x_{i+2}$ & $x_{i+3}$ & $x_{i+4}$ & $x_{i+5}$ & $x_{i+6}$ \\
\hline $\mathrm{B}_{\mathrm{i}}$ & 0 & 1 & 26 & 66 & 26 & 1 & 0 \\
$\mathrm{~B}_{\mathrm{i}}^{(1)}$ & 0 & $5 / h$ & $500 / h$ & 0 & $-502 / h$ & $-5 / h$ & 0 \\
$\mathrm{~B}_{\mathrm{i}}^{(2)}$ & 0 & $20 / h^{2}$ & $40 / h^{2}$ & $-120 / h^{2}$ & $40 / h^{2}$ & $20 / h^{2}$ & 0 \\
$\mathrm{~B}_{\mathrm{i}}^{(3)}$ & 0 & $60 / h^{3}$ & $-120 / h^{3}$ & 0 & $120 / h^{3}$ & $-60 / h^{3}$ & 0 \\
$\mathrm{~B}_{\mathrm{i}}^{(4)}$ & 0 & $120 / h^{4}$ & $-480 / h^{4}$ & $720 / h^{4}$ & $-480 / h^{4}$ & $120 / h^{4}$ & 0 \\
\hline
\end{tabular}


By substituting Eqs. (6) based on derivative degree in Eq (1), it is written as a series of linear unknown coefficients. To solve the equation over the interval, initially interval should be divided to a series of equal-spaced points. Each midpoint of the equation is obtained in terms of $\mathrm{C}_{\mathrm{i}}$.

On the other hand, let $\mathrm{x}_{0}, \mathrm{x}_{1}, \ldots, \mathrm{x}_{\mathrm{n}} \mathrm{be} \mathrm{n}+1$ grid points in interval $[a, b]$ so that $x_{i}=a+i h, i=1,2, \ldots, n, x_{0}=a, x_{n}=b, h=(b-a) / n$. As a result, $n$ equations are obtained. Each equation of $\mathrm{C}_{\mathrm{i}}$ is linear and it is in the form of $b_{1} C_{1}+b_{2} C_{2}+b_{3} C_{3}+\ldots$ where $b_{i}$ includes real number and parameter $\mathrm{P} . \mathrm{C}_{\mathrm{i}}$ is a symbolic parameter. These equations are expressed as the following matrix:

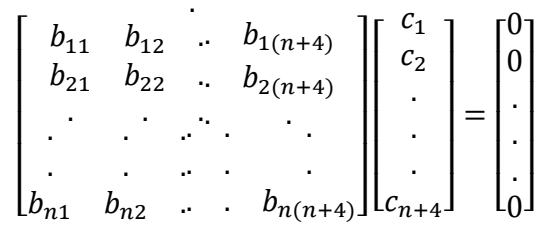

In the previous matrix, all $b_{i j}$ parameters contain real number and parameter $\mathrm{P}$. For instance, $\mathrm{b}_{12}$ is the value of function $\mathrm{B}_{1}(\mathrm{x})$ in control point $\mathrm{x}_{2}$. Above coefficient matrix is a non-squared matrix of $n \times(n+4)$ which requires four equations to be squared. Four equations are obtained by substituting B-Spline equation in the boundary conditions:

$$
\text { At } \quad x=l
$$

$$
E I \sum_{i=0}^{n} B_{i}^{(2)}(x) C_{i}+K a \sum_{i=0}^{n} B_{i}^{(1)}(x) C_{i=M b}
$$

At $\quad x=0$

$$
-E I \sum_{i=0}^{n} B_{i}^{(2)}(x) C_{i}+K a \sum_{i=0}^{n} B_{i}^{(1)}(x) C_{i=} M a
$$

At $\quad x=l$

$$
\begin{gathered}
-E I \sum_{i=0}^{n} B_{i}^{(3)}(x) C_{i}-P \sum_{i=0}^{n} B_{i}^{(1)}(x) C_{i} \\
+S b \sum_{i=0}^{n} B_{i}(x)=V b
\end{gathered}
$$

At $x=0$

$$
\begin{gathered}
E I \sum_{i=0}^{n} B_{i}^{(3)}(x) C_{i}+P \sum_{i=0}^{n} B_{i}^{(1)}(x) C_{i} \\
+S a \sum_{i=0}^{n} B_{i}(x)=V a
\end{gathered}
$$

By replacing four boundary conditions in the coefficient matrix, following squared matrix is derived:

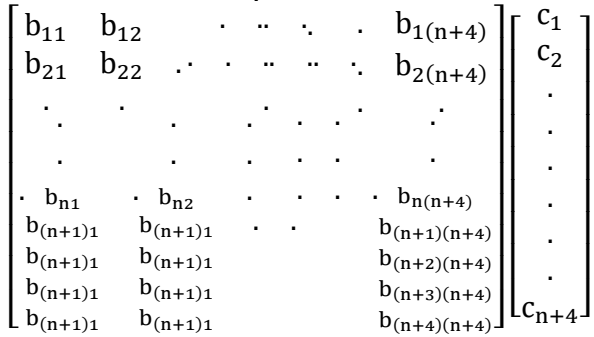

$$
\begin{aligned}
& =\left[\begin{array}{c}
0 \\
\cdot \\
\cdot \\
\mathrm{M}_{\mathrm{a}} \\
\mathrm{M}_{\mathrm{b}} \\
\mathrm{V}_{\mathrm{a}} \\
\mathrm{V}_{\mathrm{b}}
\end{array}\right]
\end{aligned}
$$

To calculate buckling critical load, determinant of coefficient matrix should be equal to zero. Thus, the matrix should be squared. In coefficient matrix, coefficients of all entries of bii are known and the only unknown parameter is Pcr. Finally, the amount of buckling critical load is calculated by equaling determinant of coefficient matrix to zero. With the proposed method, buckling critical load of the pile with various boundary conditions is simply calculated by using B-Spline method.

\section{CALCULATION OF BUCKLING LOAD WITH LATERAL SPRING IN FE MODEL}

Finite element software was used in this research program for analyzing the pile. Buckling critical load of a concrete pile was calculated. Figure 2 shows modeling of the concrete pile in the FE software. Meshing, modeling and deformation of the pile with lateral springs based on the beam on elastic base are proposed in Figure 2. It is worth noting that deformations and calculations were investigated in the first mode. In Figure 3 length of pile is $10 \mathrm{~m}$, concrete modulus of elasticity was $20 \mathrm{GPa}$ and buckling behavior of the pile was investigated.

Soil and pile behavior was in elastic range. Moreover, soil was modeled with lateral springs of the beam on elastic base. Linear perturbation, buckling analyses and subspace solver were used for modeling in the software. It is worth noting that modeling of the pile in the software was three dimensional.
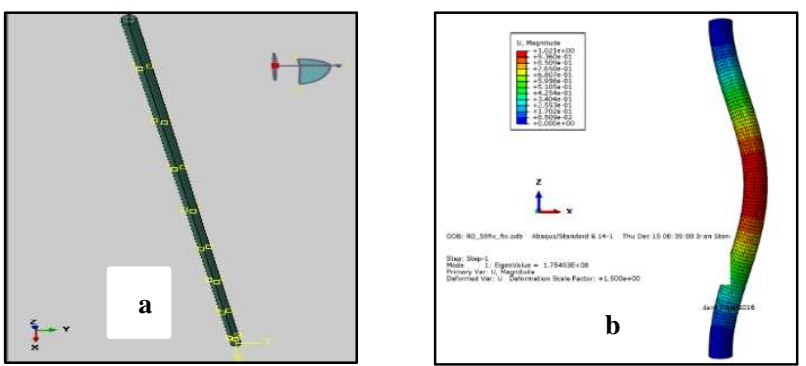

Figure 2. Modeling of pile in the FE software (a) based on the beam on elastic base (b) Pile's buckling deformation model under axial load in finite element software 


\section{COMPARING THE RESULTS AND VERIFICATION OF B-SPLINE METHOD}

In this section, buckling critical load of the pile under the effect of uniform lateral spring with B-Spline was compared with FE method and exact solution of Aristizabe-Ochoa (2013). Results of non-dimensional buckling critical load versus $\lambda$ are presented in Tables 2. Table 2 represents the results of both ends pinned and both ends fixed conditions. $\lambda$ is non-dimensional stiffness parameter as defined in Eq (10):

$$
\lambda=\sqrt{\frac{K_{s} l^{4}}{E I}}
$$

Where $E I=$ pile stiffness

$K s=$ horizontal reaction coefficient

$L=$ length of pile

Moreover, Euler's equation as defined in Eq (11) was used to make the critical load non-dimensional.

$$
P_{E}=\pi^{2} E I / L^{2}
$$

Results were compared with Table 3 proposed by AristizabeOchoa in (2013). Results showed that the values calculated by BSpline, exact solution and FE Software did not have significant difference. Therefore, proposed method of B-Spline could be used in the desired analyses.

After verification of B-Spline method in section 4, pile's buckling equation with non-uniform and nonlinear horizontal reaction coefficient is investigated in section 5 .

\section{PARAMETRIC STUDY OF PILE'S BUCKLING WITH NOLINEAR HORIZONTAL REACTION COEFFICIENT}

Any numerial analysis in engineering should be practical, applicable and usable in reality. Analysis of buckling equation is used for stability of slender columns in civil engineering. It is utilized for analysis of pile's buckling under the structure in geotechnical engineering. For more accurate use of analyses on the basis of beam on elastic base and close to reality, horizontal reaction coefficient should be modeled nonlinear or non-uniform along the column or pile (Terzaghi 1955; Davisson and Perkash 1963). Horizontal reaction coefficient is representative of materials characteristics around the column. In the case of buckling in the piles, it models horizontal reaction coefficient of the soil around the pile. Figure 3 shows variation of horizontal reaction coefficient in the forms of uniform, linear and nonlinear along the pile.

B-Spline method can modeled nonlinear horizontal reaction coefficient along the pile. For this purpose, the parameter $\mathrm{k}$ of horizontal reaction coefficient is defined as Eq (12) (Terzaghi, 1955):

$$
K_{h}=m_{h} Z^{w}
$$

where: $m_{h}=$ horizontal reaction coefficient at the bottom of the pile as shown in Figure 3.
$Z=$ depth of the pile $w=$ a coefficient to define uniform, linear and parabolic horizontal reaction coefficient.

Different values have been suggested for empirical coefficient $\mathrm{w}$ by researchers. The value of $\mathrm{w}$ have been proposed 0.1 to 5 for clay and silt soils, 1 for normal consolidated clay and granular soil and 1.5 and even up to 2 for sand soil and a type of over consolidated clay.

Table 2. Comparison of non-dimensional buckling critical load versus $\lambda$ in, (a) both ends pinned; (b) both ends fixed situations

\begin{tabular}{|c|ccc|}
\hline \multirow{2}{*}{$\boldsymbol{A}$ (Pin-Pin) } & \multicolumn{3}{|c|}{$\boldsymbol{P}_{\boldsymbol{C}} / \boldsymbol{P}_{\boldsymbol{E}}$} \\
\cline { 2 - 4 } $\boldsymbol{\lambda}=\sqrt{\frac{\boldsymbol{K}_{\boldsymbol{s}} \boldsymbol{l}^{\mathbf{}}}{\boldsymbol{E \boldsymbol { I }}}}$ & $\begin{array}{c}\text { Aristizabe-Ochoa } \\
(2013)\end{array}$ & B-spline & $\begin{array}{c}\text { FE } \\
\text { Softwere }\end{array}$ \\
\hline 5 & 1.2566 & 1.2647 & 1.2561 \\
10 & 2.0266 & 2.03643 & 2.0212 \\
15 & 3.3098 & 3.32159 & 3.3011 \\
20 & 5.0266 & 5.12080 & 4.9984 \\
40 & 8.10639 & 8.22790 & 8.0583 \\
50 & 10.41624 & 10.5408 & 10.3964 \\
60 & 13.10639 & 13.36774 & 13.0814 \\
80 & 16.30025 & 16.88197 & 16.1185 \\
100 & 20.40665 & 20.99092 & 20.1378 \\
200 & 41.42557 & 43.45451 & 40.1258 \\
500 & 101.37746 & 107.1254 & 96.1854 \\
\hline
\end{tabular}

\begin{tabular}{|c|ccc|}
\hline \multicolumn{1}{|c}{ B (Fix-Fix) } & \multicolumn{3}{c|}{$\boldsymbol{P}_{\boldsymbol{C}} / \boldsymbol{P}_{\boldsymbol{E}}$} \\
\cline { 3 - 5 } $\boldsymbol{\lambda}=\sqrt{\frac{\boldsymbol{K}_{\boldsymbol{s}} \boldsymbol{l}^{\mathbf{4}}}{\boldsymbol{E I}}}$ & $\begin{array}{c}\text { Aristizabe-Ochoa } \\
(2013)\end{array}$ & B-spline & $\begin{array}{c}\text { FE } \\
\text { Softwere }\end{array}$ \\
\hline 5 & & & \\
10 & 4.19205 & 4.2341 & 4.19125 \\
15 & 4.76276 & 4.8089 & 4.7327 \\
20 & 5.69423 & 5.74733 & 5.5827 \\
40 & 6.95763 & 7.01408 & 6.8217 \\
50 & 11.47225 & 11.66296 & 11.2257 \\
60 & 13.26391 & 13.47207 & 13.1869 \\
80 & 15.38058 & 15.61344 & 15.2268 \\
100 & 20.19018 & 20.59776 & 19.8945 \\
200 & 23.68742 & 24.24701 & 23.0148 \\
500 & 44.04601 & 45.46422 & 42.7158 \\
& 105.13392 & 111.84984 & 101.198 \\
\hline
\end{tabular}




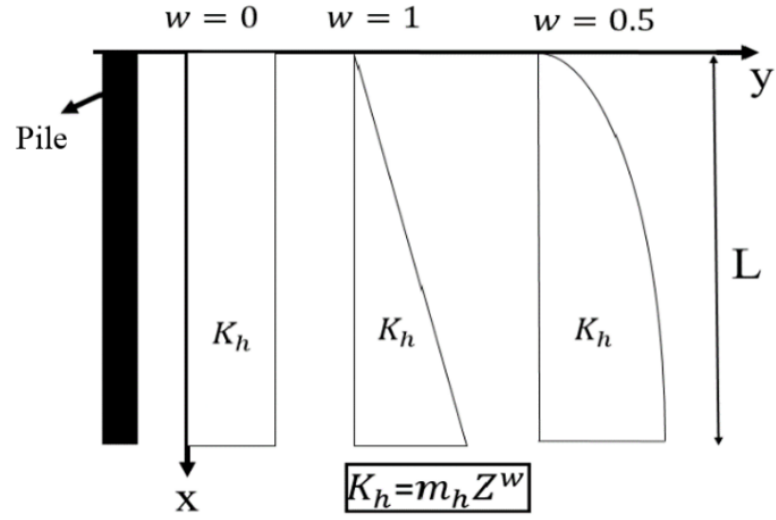

Figure 3. Uniform, linear and nonlinear variations of horizontal reaction coefficient

Non-dimensional buckling critical loads with uniform, linear or nonlinear horizontal reaction coefficient in both ends pinned and both ends fixed situations are presented in Tables 3. Results showed that the type of horizontal reaction coefficient had a significant effect on buckling critical load. Use of uniform horizontal reaction coefficient in analyses resulted in calculating critical load more than reality. Indeed, horizontal reaction coefficient is non-uniform or parabolic. For example, in the case of both ends pinned with $\lambda=50$, buckling critical load with nonlinear horizontal reaction coefficient $(\mathrm{w}=1.5)$ was about half of the one with uniform horizontal reaction coefficient $(\mathrm{w}=0)$.

The percent of difference in buckling critical load with nonlinear and non-uniform horizontal reaction coefficient than uniform one along the pile with two ends fixed and two ends pinned are presented in Figures 4 and 5, respectively.

Table 3. Buckling critical loads with various horizontal reaction coefficients in (a) both ends pinned; (b) both ends fixed situations

\begin{tabular}{|c|cccc|}
\hline A (Pin-Pin) & \multicolumn{5}{c|}{$\boldsymbol{P}_{\boldsymbol{C}} / \boldsymbol{P}_{\boldsymbol{E}}$} \\
\cline { 2 - 5 }$\lambda=\sqrt{\frac{\boldsymbol{K}_{\boldsymbol{s}} \boldsymbol{l}^{\mathbf{E}}}{\boldsymbol{E I}}}$ & $\mathrm{W}=0$ & $\mathrm{~W}=0.5$ & $\mathrm{~W}=1$ & $\mathrm{~W}=1.5$ \\
\hline 5 & & & & \\
\hline 10 & 2.0364 & 1.7154 & 1.5146 & 1.3820 \\
15 & 3.3215 & 2.5961 & 2.1406 & 1.8430 \\
20 & 5.1208 & 3.7789 & 2.9732 & 2.4552 \\
40 & 8.2279 & 6.5757 & 5.4557 & 4.6395 \\
50 & 10.5408 & 7.9847 & 6.3746 & 5.3187 \\
60 & 13.3677 & 9.5709 & 7.3769 & 6.0080 \\
80 & 16.8819 & 12.5823 & 9.4377 & 7.4369 \\
100 & 20.9909 & 15.2207 & 11.3314 & 8.8119 \\
200 & 43.4545 & 28.5074 & 19.8372 & 14.6768 \\
500 & 115.2986 & 66.0712 & 42.0943 & 29.0052 \\
\hline
\end{tabular}

\begin{tabular}{|c|cccc|}
\hline B (Fix-Fix) & \multicolumn{5}{c|}{$\boldsymbol{P}_{\boldsymbol{C}} / \boldsymbol{P}_{\boldsymbol{E}}$} \\
\cline { 2 - 5 } $\boldsymbol{\lambda}=\sqrt{\frac{\boldsymbol{K}_{\boldsymbol{s}} \boldsymbol{l}^{\mathbf{4}}}{\boldsymbol{E} \boldsymbol{I}}}$ & $\mathrm{W}=0$ & $\mathrm{~W}=0.5$ & $\mathrm{~W}=1$ & $\mathrm{~W}=1.5$ \\
\hline 5 & & & & \\
\hline 10 & 4.2341 & 4.1780 & 4.1394 & 4.1131 \\
15 & 5.7473 & 5.5813 & 4.4279 & 4.3233 \\
20 & 7.01408 & 6.14577 & 5.5492 & 5.1409 \\
40 & 11.6629 & 10.4264 & 9.0829 & 7.8633 \\
50 & 13.4720 & 11.7359 & 10.3407 & 9.1076 \\
60 & 15.6134 & 13.2241 & 11.4464 & 10.0704 \\
80 & 20.5977 & 16.7425 & 13.9076 & 11.8986 \\
100 & 24.2470 & 20.3383 & 16.6097 & 13.8585 \\
200 & 45.4642 & 36.6505 & 28.7259 & 22.9750 \\
500 & 111.8498 & 84.6319 & 61.3017 & 45.7008 \\
\hline
\end{tabular}

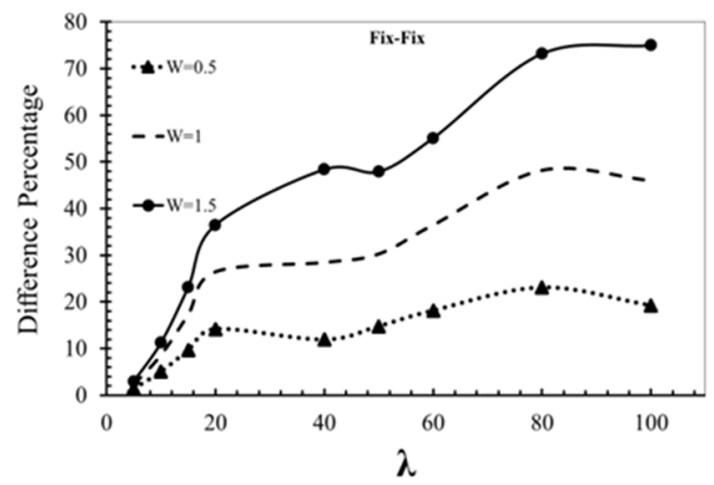

Figure 4. Percent of difference in buckling critical load with nonlinear and non-uniform horizontal reaction coefficient than uniform one along the pile with two ends fixed

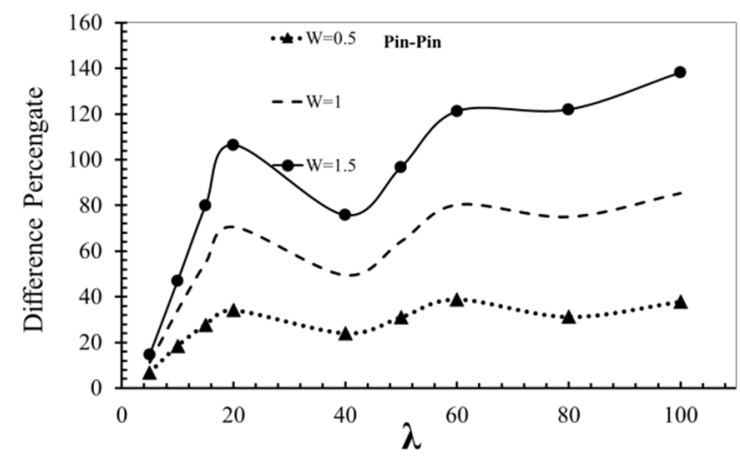

Figure 5. Percent of difference in buckling critical load with nonlinear and non-uniform horizontal reaction coefficient than uniform one along the pile with two ends Pinned

It is worth noting that maximum displacement of the pile occurs in the first mode. The range for changes of first mode to second mode in both ends fixed situation occurs in $\lambda$ equals to 30 to 40 
and in both ends pinned situation occurs in $\lambda$ equals to 20 (West et al. 1997; Heelis and West 1999; Heelis et al. 2004). According to Figure 4, if the horizontal reaction coefficient of the soil is considered uniform, the buckling critical load in the first mode is $12 \%, 35 \%$ and $55 \%$ higher than the situation with $\mathrm{w}=0.5, \mathrm{w}=1$ and $\mathrm{w}=1.5$ in both ends fixed condition, respectively. Based on Figure 5, if the horizontal reaction coefficient of the soil is considered uniform, the buckling critical load in the first mode is $35 \%, 70 \%$ and $105 \%$ higher than the situation with $\mathrm{w}=0.5, \mathrm{w}=$ 1 and $\mathrm{w}=1.5$ in both ends pinned condition, respectively. In the case of two ends pinned, this difference is much more than the one in two ends fixed pile. Because the value of pile's displacement in two ends pinned situation is higher. As mentioned before, horizontal reaction coefficient is non-uniform and nonlinear in reality. Calculation of buckling critical load with uniform horizontal reaction coefficient based on the suggestion of beams on elastic base leads to much more value than reality which causes serious risks in predicting buckling behavior of the pile.

\section{CONCLUSIONS}

In this research, B-Spline method was used for analyzing pile's buckling equations based on the beam on elastic base. This method was verified with finite element method and exact solution. Following results can be drawn:

-Results showed that B-Spline method is a leading numerical method in the analysis of pile's buckling differential equations which needs lower volume than other numerical methods such as finite element method.

- In order to get more accurate pile's buckling critical load in the case of beam on elastic base, horizontal reaction coefficient should be assumed non-uniform and nonlinear.

- By increasing the value of $\mathrm{w}$, the critical buckling load decreased. So, the equations proposed by most of the researchers based on uniform horizontal reaction coefficient with the assumption of the beam on elastic base are not precise. This difference increases with increasing the amount of $\lambda$.

- In calculating buckling critical load by using equations of the beams on elastic base for sand soils and over consolidated clay in the first mode in two ends pinned situation, this value can be estimated about two times of the real value.

\section{References}

Aristizabal-Ochoa, J.D., 2013. Stability of slender columns on an elastic foundation with generalised end conditions. Ingeniería e Investigación, 33(3), pp.34-40

Andrade, A., Providência, P. and Camotim, D., 2010. Elastic lateral-torsional buckling of restrained web-tapered Ibeams. Computers \& structures, 88(21-22), pp.1179-1196.

Bhattacharya, S. and Bolton, M., 2004. Errors in design leading to pile failures during seismic liquefaction.Fifth international conference on case Histories in Geotechnical engineering, NewYork.

Bhattacharya, S., Bolton, M.D. and Madabhushi, S.P.G., 2005. A reconsideration of the safety of piled bridge foundations in liquefiable soils. Soils and Foundations, 45(4), pp.13-25.
Chi Wai, L., 2013. Parametric studies on buckling of piles in cohesionless soils by numerical methods. Hkie Transactions, 20(1), pp.12-33.

Caglar, H. and Caglar, N., 2008. Fifth-degree B-spline solution for a fourth-order parabolic partial differential equations. Applied Mathematics and Computation, 201(1-2), pp.597-603.

Caglar, H., Caglar, N. and Ozer, M., 2008. Fifth-degree B-spline solution for nonlinear fourth-order problems with separated boundary conditions. In Journal of Physics: Conference Series (Vol. 96, No. 1, p. 012031). IOP Publishing.

Davisson, M.T. and Prakash, S., 1963. A review of soil-pole behavior. Highway Research Record, (39).

Deng, T., Liu, Q. and Huang, M., 2017. Buckling of Fully Embedded Single Piles by Using the Modified Vlasov Foundation Model. International Journal of Structural Stability and Dynamics, 17(01), p.1750007.

De Boor., 1978. A practical guide to splines (Vol. 27, p. 325). New York: Springer-Verlag.

Hetenyi, M L., 1960. Beam on elastic foundation. University of Michigan Press, pp.110-140.

Heelis, M.E. and West, R.P., 1999. The stability of uniformfriction piles inhomogeneous and non-homogeneous elastic foundations. International journal of solids and structures, 36(22), pp.3277-3292.

Heelis, M.E., Pavlović, M.N. and West, R.P., 2004. The analytical prediction of the buckling loads of fully and partially embedded piles. Geotechnique, 54(6), pp.363-373.

Moghadam, S.N., Asgarian, B. and Nazokkar, K., 2012. Simulation of overall and local buckling behavior of cylindrical tubular members using fuzzy inference system. Advances in Engineering Software, 45(1), pp.349-359.

Mittal, R.C. and Jain, R.K., 2011. B-splines methods with redefined basis functions for solving fourth order parabolic partial differential equations. Applied Mathematics and Computation, 217(23), pp.9741-9755.

Piegl, L. and Tiller, W., 1995. The NURBS Book, SpringerVerlag. New York.

West, R.P., Heelis, M.E., Pavlović, M.N. and Wylie, G.B., 1997. Stability of end-bearing piles in a non-homogeneous elastic foundation. International journal for numerical and analytical methods in geomechanics, 21(12), pp.845-861.

Shariyat, M. and Asemi, K., 2014. 3D B-spline finite element nonlinear elasticity buckling analysis of rectangular FGM plates under non-uniform edge loads, using a micromechanical model. Composite Structures, 112, pp.397-408.

Terzaghi, K., 1955. Evalution of conefficients of subgrade reaction. Geotechnique, 5(4), pp.297-326. 